\title{
Red Colour Comparison Perimetry Chart in Neuro- Opthalmological Examination
}

\author{
ERKAN MUTLUKAN and JAMES F. CULLEN \\ Edinburgh
}

\begin{abstract}
Summary
A new test chart has been developed as a quick, alternative and supplementary method of perimetric evaluation of the central 25 degrees of the visual field to test for the presence of relative and absolute scotomas as part of a routine eye and neurological examination. The result of a comparison of this test with formal perimetry in 107 patients is described and discussed.
\end{abstract}

Taken together with visual acuity and colour vision, perimetric tests can provide information essential to a clear understanding of the integrity of a patient's visual system. Perimetry is a key aid to diagnosis of neurological conditions affecting the pathway from the eye to the occipital cortex.

A proportion of neurological and neurosurgical patients have difficulty in sustaining the necessary cooperation for accurate perimetry. Therefore, charting of the visual fields of such patients may sometimes be omitted. In other settings, formal perimetry is impractical or too time consuming to be used on routine clinical examination. A perimetric test chart based on red colour comparison technique has been designed to overcome these problems, and has been compared with conventional perimetry.

\section{Method}

The chart has nine disc-shaped test targets on both sides, one in the centre and the others in the surrounding periphery. Targets were made of a vivid red colour. The background was black on one side of the test chart creating a $50 \%$ contrast gradient, and grey on the reverse side of the card, creating a $75 \%$ contrast gradient (Figs 1, 2. Patent pending).

Target distribution was arranged to correspond to the central $25^{\circ}$ of the visual field when held at $30 \mathrm{~cm}$ distance from and parallel to the eye. Two test spots were positioned in each quadrant, avoiding the vertical and horizontal meridians. (Figs 3,4). The centre of the chart was marked with a $1 \mathrm{~mm}$ black dot to be used as a fixation point.

Patients referred to a neuro-ophthalmology clinic were tested with their best spectacle correction for distance, in a diffusely illuminated room with a constant level of illumination. Direct 1ight sources behind and in front of the patient were avoided.

Each patient was first questioned to exlude congenital achromatopsia and had a full neuro-ophthalmic examination including colour vision testing with $\mathrm{H}-\mathrm{R}-\mathrm{R}$ plates. Incorrect identification of more than two plates was considered abnormal. The red comparison perimetry chart was then shown to the patient and explained. Each eye was tested with both the gray and black background. Right eyes were tested first. The patient was asked to fix on the central spot,

Financially supported by: W H Ross Foundation for the Prevention of Blindness (Scotland).

Correspondence to: Royal Infirmary of Edinburgh, Princess Alexandra Eye Pavilion, Edinburgh EH3 9HA, Scotland. 

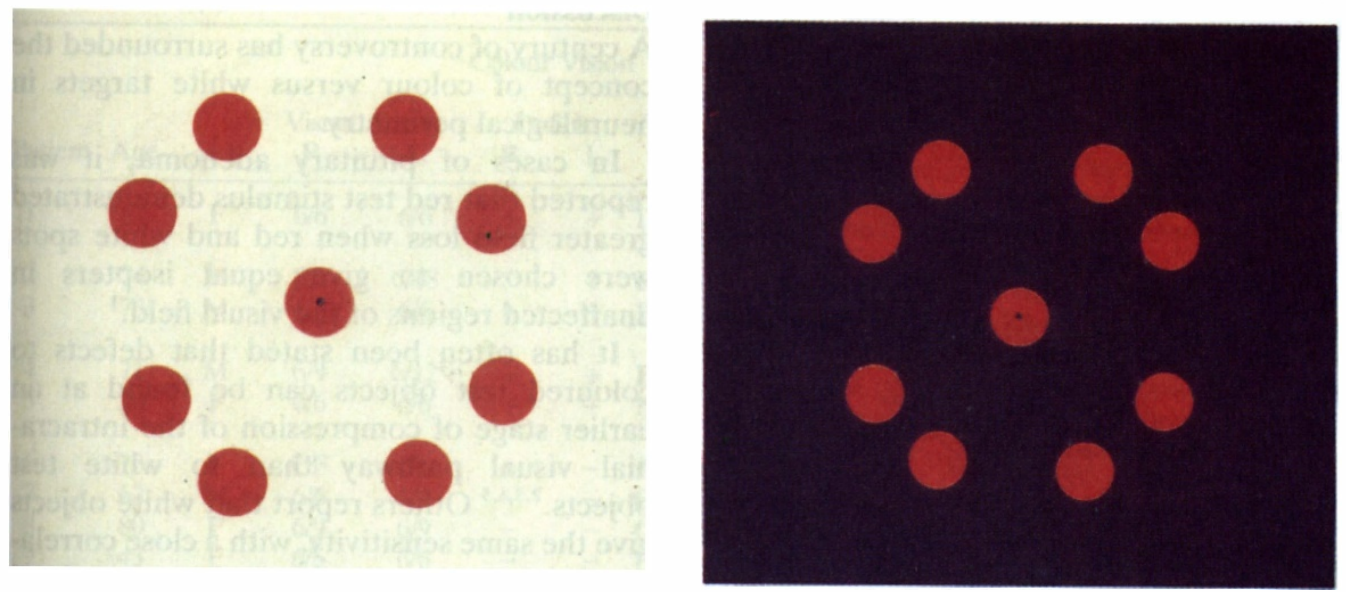

Figs. 1 and 2 Red colour comparison perimetry chart; gray and black background.

central disc or at the approximate centre of the chart according to their visual acuity level and while fixation to the centre was continuously checked and encouraged, they were asked to indicate the total number of discs seen. Missing targets implied the presence of an absolute scotoma. Cases reporting any missing targets were asked if blinking a few times caused the targets to reappear. They were then asked to indicate if any target(s) had washed-out colours (e.g pale, pinkish, dark yellow, gray) compared to the others in order to identify relative scotomas. All patients were subsequently examined with Bjerrum $2 \mathrm{~m}$. Screen perimetry was by a second observer who was unaware of the previous findings. Fields to white and red targets were plotted.

Patients with congenital colour vision anomalies and normal fields were excluded from the study. Results in subjects with congenital achromatopsia and neurological field deficit were evaluated only with regard to the total number of disc patterns seen.

\section{Results}

One-hundred-and-seven patients, 39 females and 68 males, aged between 19 and 80 years were examined. All had normal pupils sized 3-7 $\mathrm{mm}$. Thirty-three patients had visual field abnormalities on Bjerrum screening. Two patients who had glaucomatous field defects, one senile maculopathy case with central sco- toma, one individual who was considered to have hysterical field examination findings (with normal chart result), one patient with poor cooperation and fixation and a patient with neurological field defect outside the central $20^{\circ}$ (in total six patients) were excluded from the study. Among the remaining 27 patients listed in Table I, 16 cases (26 eyes) had absolute, seven cases (11 eyes) had relative and four patients ( 7 eyes) had combined relative and absolute field defects. Seventyfour patients did not show any abnormal Bjerrum Screen findings. There were no differences in patient responses to grey and black test backgrounds, other than more frequent episodes of transient disappearance of the disc patterns on black background, due to fast local adaptation. Case 10 and 22 in Table I had congenital achromatopsia.

The test had $92 \%$ sensitivity and $96 \%$ specificity with $4 \%$ false positive and $7.4 \%$ false negative results in detecting the presence of any field loss within the central $25^{\circ}$ when compared with $2 \mathrm{~m}$. Bjerrum Screen testing. Positive and negative predictive values of the test were $90 \%$ and $97 \%$, respectively.

Correlation between the actual extent of the defect found on Tangent Screen perimetry and reported abnormalities of the corresponding disc patterns on the chart were studied further. Patients with macular splitting on Tangent Screen perimetry usually described the central red disc as intact. This was attri- 


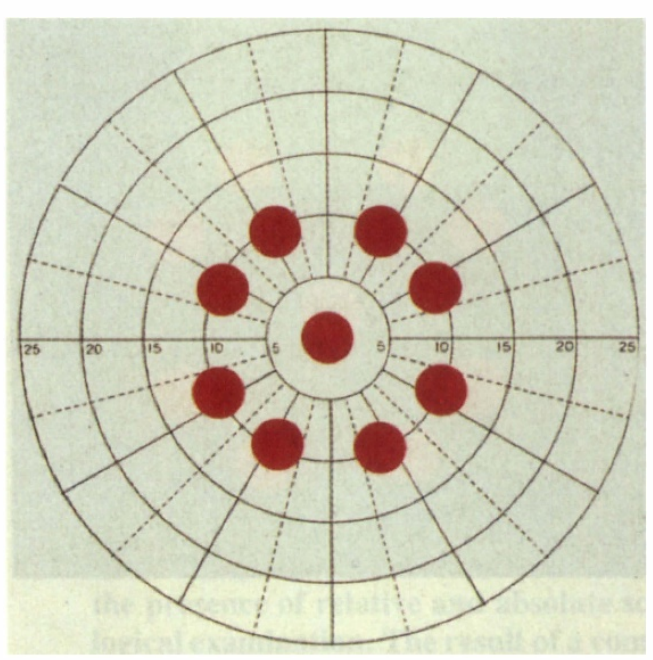

Fig. 3 Test spot positions superimposed on a Tangent Screen.

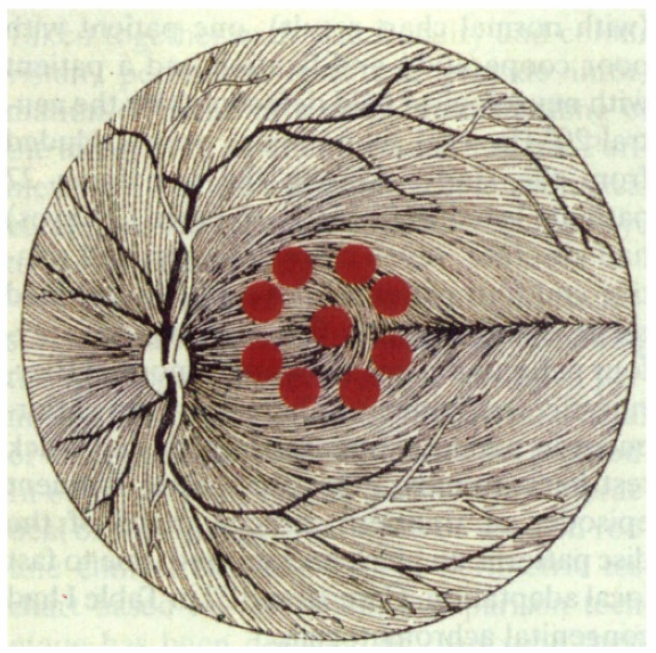

Fig. 4 Test spot positions superimposed on the retina.

buted to the patient's possible tendency to extrafoveal fixation. The chart was found to be $89 \%$ sensitive and $95 \%$ specific in determining the boundaries of the Tangent Screen field defect with $4.8 \%$ false positive and $10.5 \%$ false negative findings and with a positive predictive value of $93 \%$ and a negative predictive value of $92 \%$. Formal perimetry results and test chart findings of seven patients are shown on Tables II-VIII.

\section{Discussion}

A century of controversy has surrounded the concept of colour versus white targets in neurological perimetry.

In cases of pituitary adenoma, it was reported that red test stimulus demonstrated greater field loss when red and white spots were chosen to give equal isopters in unaffected regions of the visual field. ${ }^{1}$

It has often been stated that defects to coloured test objects can be found at an earlier stage of compression of the intracranial visual pathway than to white test objects. ${ }^{2,3,4,5}$ Others report that white objects give the same sensitivity, with a close correlation between chromatic and achromatic visual loss if minimum stimulii are used, or if achromatic and chromatic stimuli of equal size are matched for intensity. ${ }^{6,7}$

In colour perimetry, each coloured object has two endpoints: target recognition (achromatic endpoint) and colour recognition (chromatic endpoint). The former always gives a larger isopter for a given colour as the stimulus threshold for colour recognition is several times higher than its visibility.

It has been suggested that this difference might relate to the sampling interval for magnocellular and parvocellular neurons in the human visual system. ${ }^{8}$ According to contemporary theories the magnocellular system ( $\mathrm{P}$ Alfa ganglion cells) is insensitive to colour contrast but has a high sensitivity to luminance contrast. Conversely, the parvocellular system (P Beta ganglion cells) is less sensitive to luminance contrast but processes colour information. Although colour can probably only be processed by the parvocellular system, visibility might conceivably be mediated by both systems. ${ }^{9}$ Positron emission tomographic scanning during visual stimulation with stationary and moving coloured and isoluminant ahcromatic patterns has demonstrated that two anatomically distinct areas of human prestriate cortex are involved in processing of colour and motion. ${ }^{10}$ Several cases of hemiachromatopsia have been described. ${ }^{11}$ Homonymous field defects can themselves introduce errors in colour arrangement tests such as the FM 100-hue test. $^{12}$

In patients with pronounced congenitalco- 
Table 1 List of patients with visual field defects.

\begin{tabular}{|c|c|c|c|c|c|c|c|c|}
\hline \multirow[b]{3}{*}{ Patient } & \multirow[b]{3}{*}{ Age } & \multirow[b]{3}{*}{ Sex } & \multicolumn{5}{|c|}{ Colour Vision } & \multirow[b]{3}{*}{ Field Defect } \\
\hline & & & Visual & Acuity & & & & \\
\hline & & & $\mathbf{R}$ & $\mathrm{L}^{-}$ & $\mathbf{R}$ & $\mathbf{L}$ & Pathology & \\
\hline 1 & 67 & F & $6 / 6$ & $6 / 6$ & + & + & L. Temporo-Occipital SOL & $\begin{array}{l}\text { R. Sup. Homonymous } \\
\text { Quadrantopsia }\end{array}$ \\
\hline 2 & 74 & $\mathbf{M}$ & PL & $6 / 18$ & & + & Pituitary Adenoma & R. Hemianopia \\
\hline 3 & 73 & $\mathbf{M}$ & $6 / 6$ & $6 / 6$ & + & + & Pituitary Adenoma & $\begin{array}{l}\text { L. Hemianopia; R. Sup. } \\
\text { Altitudinal Defect }\end{array}$ \\
\hline 4 & 71 & $\mathbf{M}$ & $6 / 9$ & $6 / 12$ & + & + & Pituitary Adenoma & Bitemporal Hemianopia \\
\hline 5 & 20 & $\mathbf{F}$ & $6 / 6$ & $6 / 6$ & + & + & Pituitary Adenoma & $\begin{array}{l}\text { Bitemporal Superior } \\
\text { Quandrantopsia }\end{array}$ \\
\hline 6 & 73 & $\mathrm{~F}$ & $\mathrm{CF}$ & $6 / 6$ & + & - & R. AION & L. Inferior Altitudinal Defect \\
\hline 7 & 62 & $\mathbf{M}$ & $6 / 6$ & $6 / 6$ & - & - & Occipital SOL & L. Homonymous Hemianopia \\
\hline 8 & 80 & $\mathbf{F}$ & $6 / 9$ & $6 / 9$ & - & - & Occipital Lobe Infarction & L. Homonymous Hemianopia \\
\hline 9 & 43 & $\mathrm{~F}$ & $6 / 6$ & $6 / 6$ & - & - & Empty Sella Syndrome & R. Homonymous Hemianopia \\
\hline 10 & 37 & $\mathbf{M}$ & $6 / 60$ & $6 / 6$ & + & + & Internal Capsular Infarct? & R. Nasal Hemianopia \\
\hline 11 & 25 & $\mathbf{M}$ & $6 / 9$ & $\mathrm{CF}$ & + & + & Multiple Sclerosis & $\begin{array}{l}\text { R. Inferior Altitudinal Defect } \\
\text { and Central scotoma }\end{array}$ \\
\hline 12 & 28 & $\mathbf{F}$ & $6 / 6$ & $6 / 6$ & - & - & Multiple Sclerosis & $\begin{array}{l}\text { R. Sup. Temporal } \\
\text { Quadrantopsia }\end{array}$ \\
\hline 13 & 55 & $\mathbf{M}$ & $6 / 6$ & $6 / 36$ & - & + & L. AION & L. Sup. Altitudinal Defect \\
\hline 14 & 33 & $\mathbf{M}$ & $6 / 6$ & $6 / 6$ & - & + & Empty Sella Syndrome & $\begin{array}{l}\text { R. Sup. Altitudinal Defect } \\
\text { L. Inf. Altitudinal Defect }\end{array}$ \\
\hline 15 & 44 & $\mathbf{M}$ & $6 / 6$ & $6 / 6$ & - & - & Occipital lobe Infarction & $\begin{array}{l}\text { R. Homonymous Sup. } \\
\text { Quadrantopsia }\end{array}$ \\
\hline 16 & 26 & $\mathbf{M}$ & $6 / 6$ & $6 / 6$ & + & + & Craniopharyngioma & $\begin{array}{l}\text { L. Homonymous Incongrous } \\
\text { Defect }\end{array}$ \\
\hline 17 & 28 & $\mathbf{M}$ & $6 / 5$ & HM & - & + & Craniopharyngioma & $\begin{array}{l}\text { R. Temporal Hemianopia } \\
\text { L. Central Scotoma }\end{array}$ \\
\hline 18 & 56 & $\mathbf{F}$ & $6 / 9$ & $6 / 60$ & + & + & Suprasellar SOL & $\begin{array}{l}\text { R. Temporal Hemianopia } \\
\text { L. Central Scotoma }\end{array}$ \\
\hline 19 & 71 & $\mathbf{M}$ & - & HM & & & Pituitary Adenoma & L. Temporal Hemianopia \\
\hline 20 & 59 & $\mathbf{M}$ & $6 / 6$ & $6 / 9$ & + & + & Occipital Lobe Infarct & R. Homonymous Hemianopia \\
\hline 21 & 60 & $\mathbf{M}$ & $6 / 24$ & $6 / 6$ & + & - & R. Posterior NAION & R. Superior Altitudinal Defect \\
\hline 22 & 71 & $\mathbf{M}$ & $6 / 36$ & $6 / 36$ & + & + & Parieto-temporal Infarct & L. Homonymous Hemianopia \\
\hline 23 & 27 & $\mathbf{F}$ & $6 / 9$ & $6 / 5$ & + & - & R. Retrobulbar O. Neuritis & R. Central Scotoma \\
\hline 24 & 29 & $\mathbf{F}$ & $6 / 12$ & $6 / 5$ & + & - & R. Retrobulbar O. Neuritis & R. Centrocecal Scotoma \\
\hline 25 & 54 & $\mathbf{M}$ & $6 / 9$ & $6 / 6$ & + & + & Pituitary Adenoma & Bitemporal Hemianopia \\
\hline 26 & 59 & $\mathbf{M}$ & $6 / 5$ & $6 / 5$ & - & - & Occipital Lobe Infarct & Bilateral Paracentral Scotoma \\
\hline 27 & 58 & $\mathbf{M}$ & $6 / 5$ & $6 / 6$ & + & + & Occipital Skull Fracture & $\begin{array}{l}\text { Bilateral L. Sup. } \\
\text { Quadrantopsia }\end{array}$ \\
\hline
\end{tabular}

SOL: Space occupying lesion, AION: Anterior ischaemic optic neuropathy, NAION: Non-arteritic ischaemic optic neuropathy, Sup: superior, O: optic, R: right, L: left.

lour defects or lack of appreciation of coloured stimuli due to an acquired lesion of the central nervous system, perimetry with chromatic targets is virtually meaningless. ${ }^{13,14}$

In a relative scotoma, visual sensation is reduced because of a change in visual threshold associated with a subjective reduction of brightness. In colour comparison testing, subjective sense of brightness depends on how far above threshold the stimulus is. Thus, a stimulus can appear less bright, and of differ- ent colour, in a region where sensitivity is reduced because its intensity exceeds the threshold stimulus value by a lesser amount than it does in the normal portion of the visual field. Differences in colour saturation are more easily appreciated than brightness. ${ }^{15} \mathrm{~A}$ red object, for instance, might seem maroon in the defective field area, and bright red in the adjacent normal area. This effect may be used to confirm the results of conventional perimetric methods. During colour compari- 

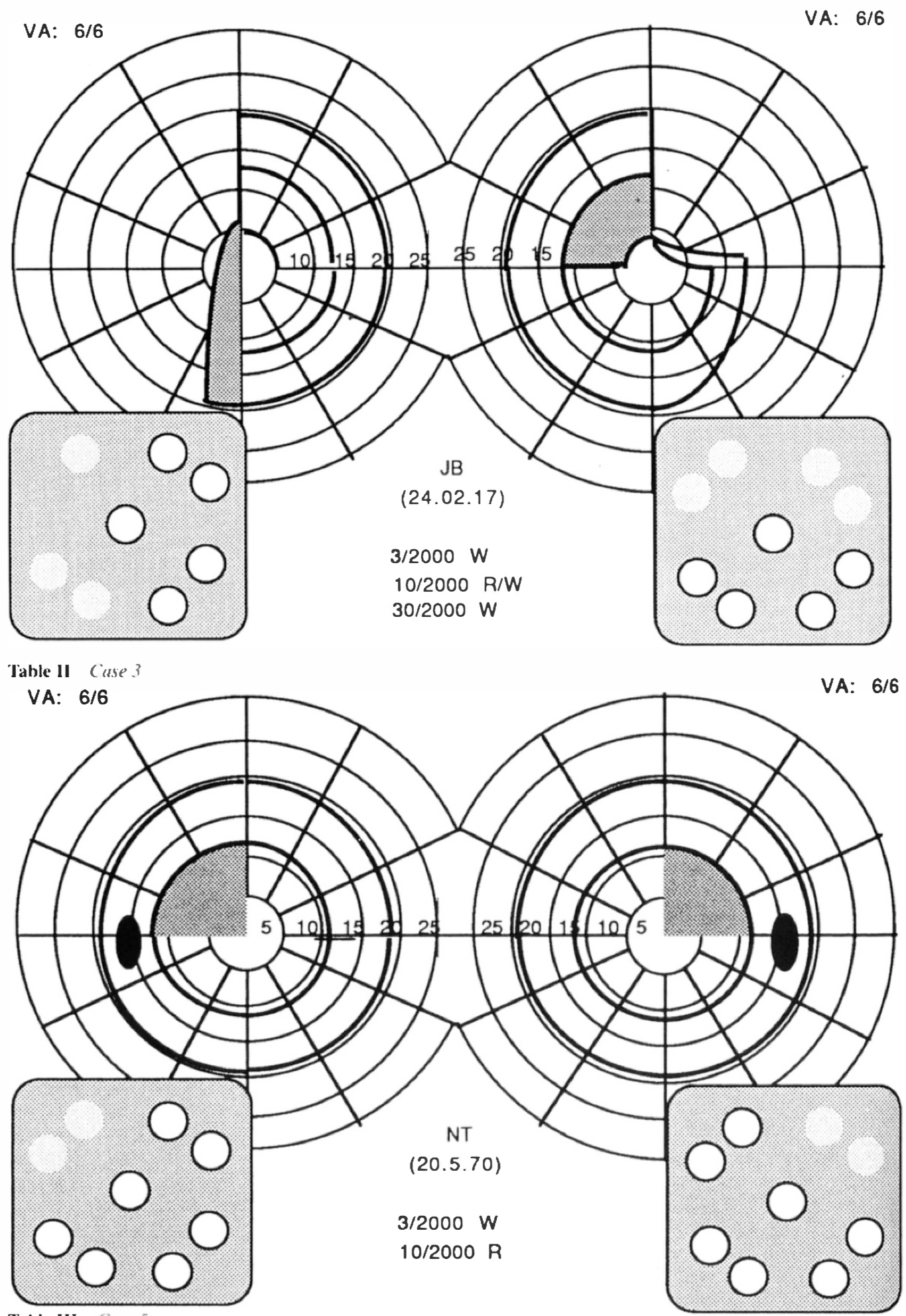

Table III Case 5 


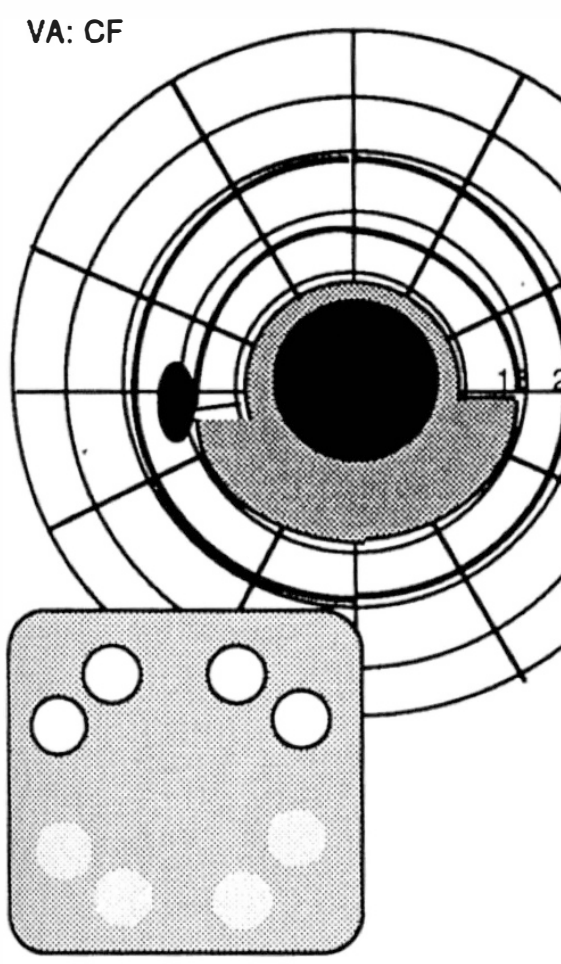

VA: $6 / 9$

Table IV ( ine //

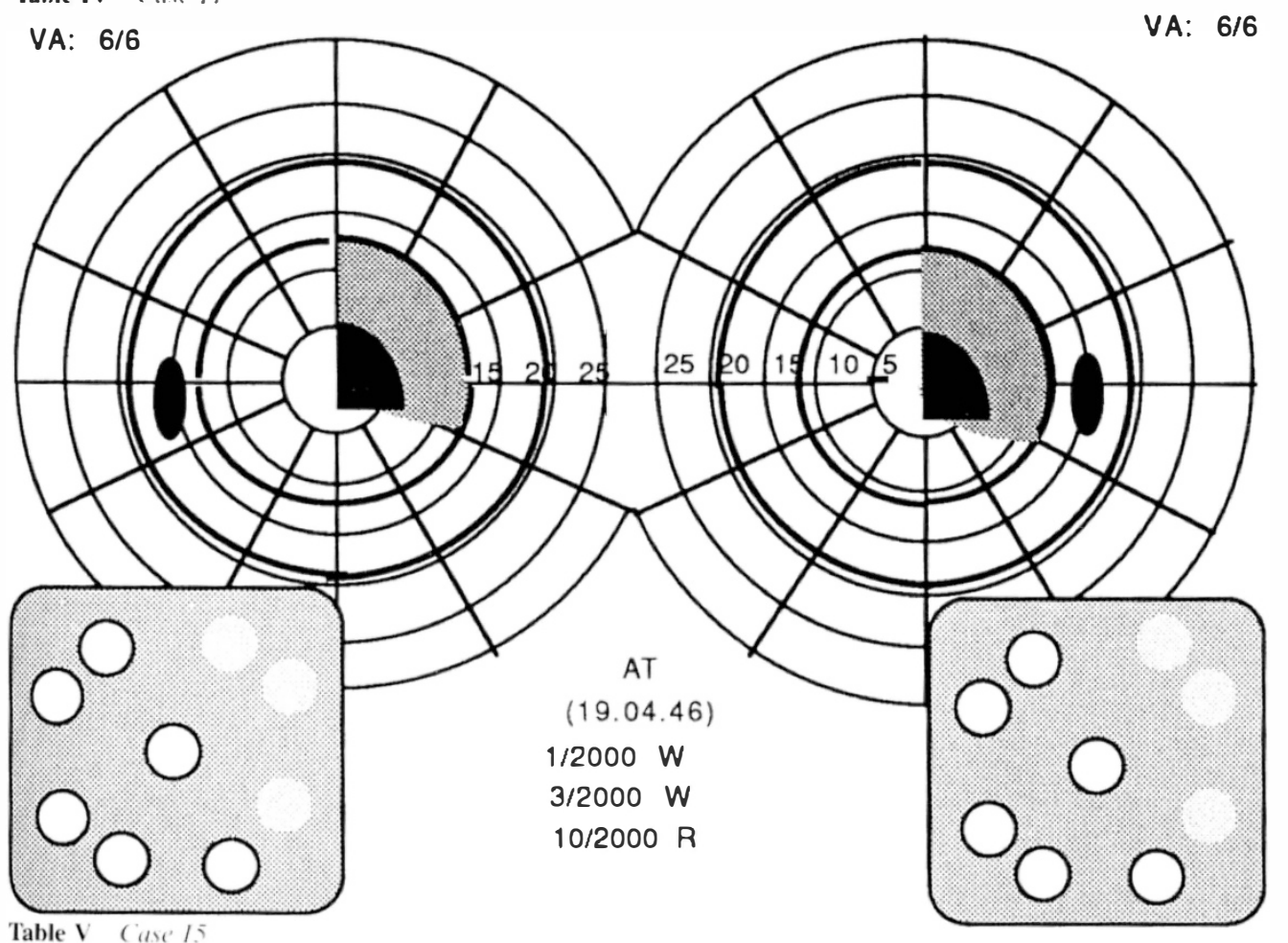

$(31.01 .65)$

$3 / 2000 \mathrm{~W}$

$5 / 2000 \mathrm{~W}$

10/2000 W, R

$30 / 2000 W, R$
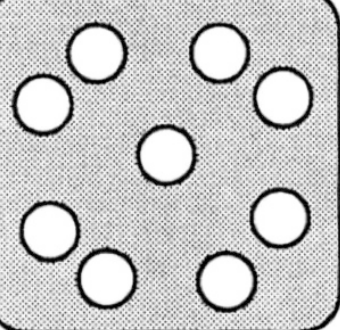

VA: $6 / 6$ 


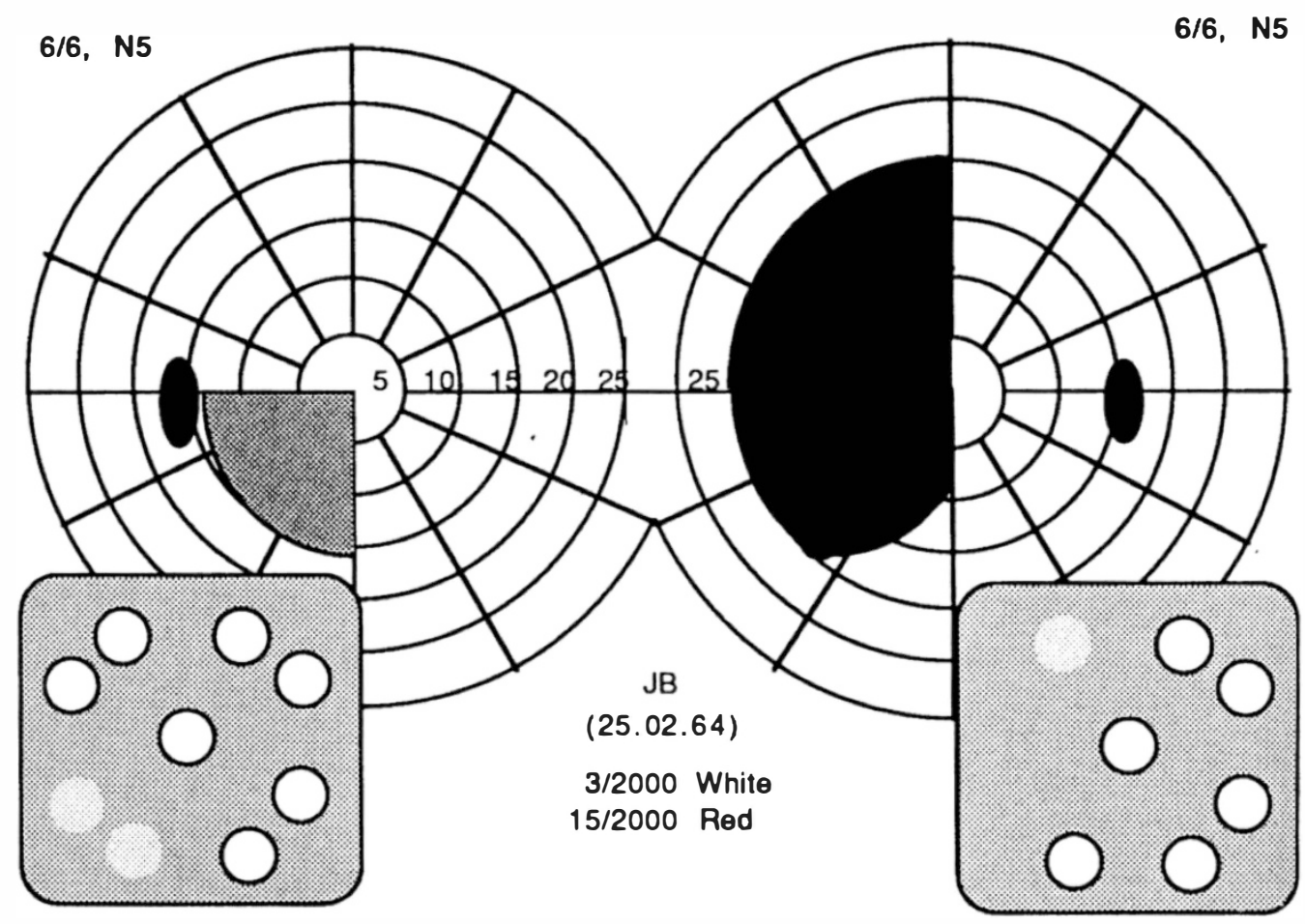

Table VI Case 16

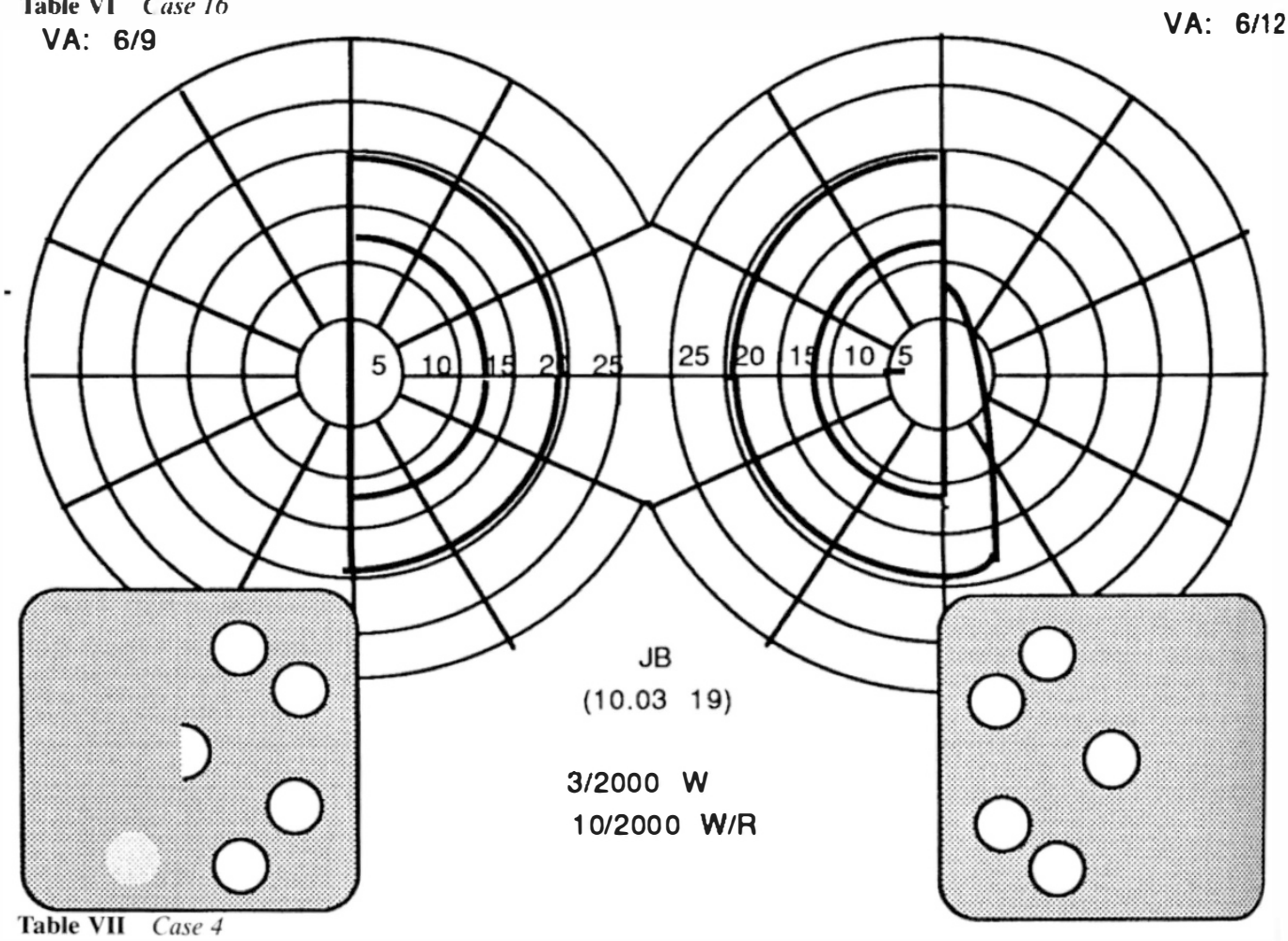




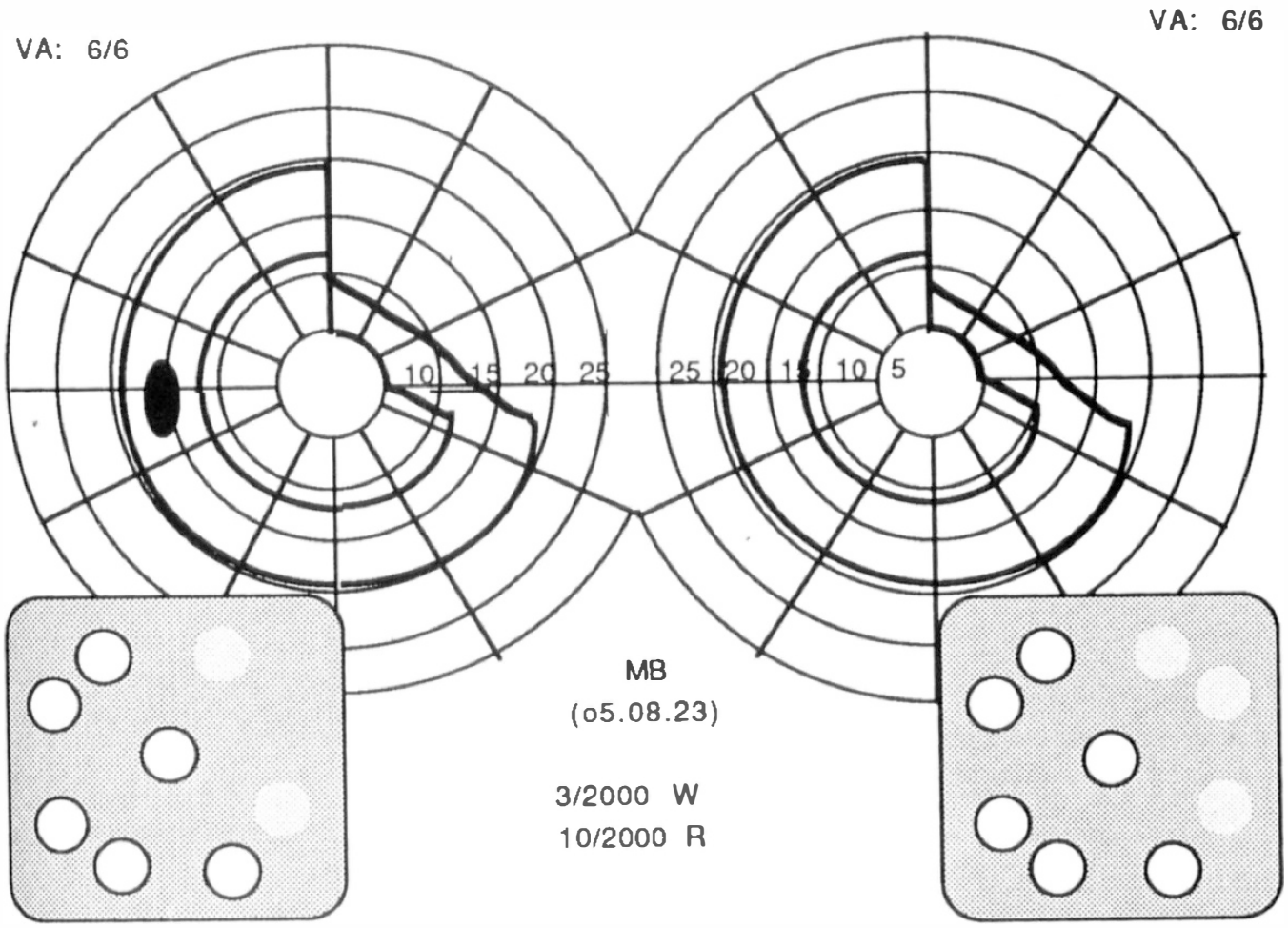

Table VII Case 1

sion testing, the first response should receive the greatest attention and the colour difference should be instantly obvious to the patient. If a patient has to think about it, the test is unreliable. ${ }^{15}$ In order to reveal scotomas using the simultaneous comparison technique, patients are asked to compare red coloured stimuli located on multiple sites on the chart, both in the centre and in the surrounding area and report whether they are all of the same appearance or whether there are different or missing ones.

Confrontation technique using white and red-headed hatpins was advocated by Kestenbaum in $1948 .{ }^{16}$ Commonly encountered inadvertent surface reflection on the coloured sphere part of the pin is a major drawback of this widely used technique. Its modification by examining with a green or red coloured torch ${ }^{17}$ has the disadvantage of a lack of background neutrality.

The ease, rapidity and sensitivity of the Amsler grid $^{18}$ for accurate detection of central scotomas is well established and specific responses to the Amsler grid test are most commonly seen in patients with macular lesions. One of the Amsler test plates is made up of red lines on a black surface for colour field testing. However, this grid has limitations when used to detect relative scotomas of neurological origin, except for prechiasmal visual pathway disorders causing a field defect very centrally. The red lines are so thin and dim on the dark background that even intelligent patients with normal visual fields and acuities miss them. ${ }^{14}$ This phenomenon is due to rapid local light adaptation (Troxler's phenomenon), which is inherent with eccentrically fixated white or coloured objects. When a small stationary target is carefully fixated by an observer, it is found that an object seen in the area surrounding the fixation point fades out after a few seconds and disappears completely. As the peripheral target disappears, its background seems to fill in the area it occupied. The steadier the fixation the more pronounced is Troxler's effect for a given observer, with a wide range of observer variation.

The Troxler phenomenon depends mainly 
on neural rather than photochemical action and the lateral geniculate body has been suggested as the seat of the effect. ${ }^{19}$ The weaker the stimuli (smaller or dimmer), the more easily can the effect be demonstrated. ${ }^{20}$ The persistence time of the object apparently increases with the number of receptive cells excited by the stimulus, since the disappearance takes longer with increasing target size, stimulus border enhancement and temporal modulation at a given eccentricity. ${ }^{21,22}$ Once the target has disappeared, a short discontinuity of fixation restores its visability.

For these reasons, our test charts were designed with large target sizes and two different contrast gradients between the targets and the background. Patients were asked to blink in order to minimise the local light adaptation effect.

Although it is well known that a tangent screen is simple and inexpensive and, when used with skill, can provide entirely adequate screening, diagnostic and quantitative field examination, ${ }^{15,23}$ it may not appear to be the best method to act as the 'Gold Standard' in the assessment of a new technique. However, we preferred to compare the RCCP Chart against Bjerrum Screen Campimetry as the latter has a wide use in routine neuroophthalmic practice due to its practical convenience and definite advantage of quick diagnostic examination.

Chiasmatic lesions may primarily effect only the decussating nasal-macular fibres, resulting in a 'central bitemporal hemianopia'. Only the area up to $10^{\circ}$ from fixation is involved with normal peripheral fields. Any lesion affecting the tip of the occipital lobe produces a defect involving only the central homonymous hemifields ${ }^{24}$ with macular sparing (corresponding to the central disc pattern of the test chart which subtends $3^{\circ}$, thus testing the blind zone of the Goldmann perimeter). We believe this chart is especially useful in detecting such lesions, in addition to optic tract and radiation defects.

Lesions involving Meyer's loop, peripheral field defects caused by lesions of the upper calcarine fissure and some isolated paracentral scotomas, would not be detected by these charts. However, such lesions and their secon dary perimetric changes are rarely encoun tered.
The patients in our preliminary study had a very high incidence $(31 \%)$ of visual field pathology. That is because they were seen by a physician before their visual fields were tested. They were only referred to the formal neuro-ophthalmology service if the physician had a reasonable suspicion that a field defect might be present following screening by history and physical examination. Therefore, the screening value of the RCCP Chart in the general population, in which the incidence of abnormal visual fields is $3-4 \%$ up to age $65,{ }^{25}$ remains to be determined with further studies.

We have found the red colour comparison perimetry chart is a useful adjunct to conventional perimetry in routine neuro-ophthalmic examinations. In addition, reliable information may be obtained from patients who cannot co-operate sufficiently to perform conventional perimetry.

Key Words: Perimetry, Colour Perimetry

\section{References}

${ }^{2}$ Bartolli F and Liuzzi L: Laser Perimetry: Diagnostic application in six cases of pituitary adenoma. Acta Ophthalmol 1973, 51: 841-52.

${ }^{2}$ Enoksson P: Perimetry in Neuro-Ophthalmological Diagnosis. Acta Ophthalmologica 1965, 43 (Suppl 82): $1-54$

${ }^{3}$ King-Smith PE, Lubow M, Benes SC: Selective damage to chromatic mechanisms in neuro-ophthalmic diseases. Doc Ophthalmol 1984, 58: 241-50.

${ }^{4}$ Bailey JE: The status of colour fields today. $J$ Am Optom Ass 1980, 51: 843-7.

${ }^{5}$ Hedin A and Verriest G: Is clinical colour perimetry useful? Doc Opthalmol Proc Ser 1981, 26: 161-84.

${ }^{6}$ Mindel JS: Visual field testing with red targets. Arch Ophthalmol 1983, 101: 927-9.

${ }^{7}$ Hart WH and Burde RM: Colour Contrast Perimetry. Ophthalmology 1985, 92: 768-76.

${ }^{8}$ Drasdo $\mathrm{N}$ and Thompson CM: Do visibility and colour recognition isopters relate to the distribution $\mathrm{Pd}$ and $\mathrm{P} \beta$ ganglion cells of the retina? Ophthal, Physiol Opt 1989, 9: 447-50.

${ }^{9}$ Zeki S and Shipp S: The functional logic of cortical connections. Nature (London) 1988, 335: 311-17.

${ }^{10}$ Lueck CJ and Zeki S: Demonstration of functional specialisation in human prestriate cortex using positron emission tomography. The London Hospital, UK. Presented at 8th International NeuroOphthalmology Symposium, Winchester, England. June 1990.

${ }^{11}$ Kolmel HW: Pure homonymous hemiachromatopsia. Findings with neuro-ophthalmic examination 
and imaging procedures. Eur Arch Psychiatry Neurol Sci 1988, 237: 237-43.

${ }^{12}$ Zihl J: The influence of homonymous visual field disorders on colour sorting performance in the FM 100-hue test. Neuropsychologia 1988, 26: 869-76.

${ }^{13}$ Walsh TJ: Neuro-ophthalmology. Clinical Signs and Symptoms. 2nd Edition. Lea-Febiger, 1985.

${ }^{14}$ Meadows JC: Disturbed perception of colours associated with localized cerebral lesions. Brain 1974, 97: 615-32.

${ }^{15}$ Anderson DR: Perimetry with and without automation. 2nd edition, The CV Mosby Company, 1987.

${ }^{16}$ Duke-Elder S: Investigation of Indirect Vision: The visual fields. System of Ophthalmology. Vol VII:393-421. Henry Kimptom, London, 1962.

${ }^{17}$ Frisen LA: Versatile Color Confrontation Test for the Central Visual Field. Arch Ophthalmol 1973, 89: 3-9.

${ }^{18}$ Amsler M: Earliest Symtoms of the Diseases of the Macula. Br J Ophthalmol 1953, 37: 521-37.
${ }^{19}$ Clarke FJ and Belcher SJ: On the localization of the Troxler's effect in the visual pathway. Vision Res 1962, 2: 53-63.

${ }^{20}$ Cibis S: Zur pathologie der lokal adaptation. $v$ Grafes Arch Ophthalmol, 148: 216-57.

${ }^{21}$ Moses RA: Adler's Physiology of the Eye. Clinical Application. 7th Edition. The CV Mosby Company, 1981.

${ }^{22}$ Dawson WW, Michels M, Semple-Rowland SL: Results from a Simple Laser Colour Perimeter. Docu Ophthalmol 1984, 57: 181-6.

${ }^{23}$ Portney GL and Rubenzer MA: Comparisons of Glaucomatous Visual Fields Using the Black Tangent Screen and the Goldmann Perimeter. Surv Ophthalmol 1972, 17: 164-7.

${ }^{24}$ Bajandas FJ and Kline LB: Neuro-Ophthalmology Review Manual. Third Edition. Slack Incorporated, USA (1989) 1-23.

${ }^{25}$ Johnson CA and Keltner JL: Incidence of Visual Field Loss in 20,000 Eyes and Its Relationship to Driving Performance. Arch Ophthalmol 1983, 101: 371-5. 